\title{
Efektifitas buku panduan uji sentuh ipswich dalam meningkatkan keterampilan kader kesehatan mendeteksi neuropati diabetik
}

\author{
Suyanto*, Sri Lestari Dwi Astuti \\ Politeknik Kesehatan Surakarta Jurusan Keperawatan. ”Email: suyanto.mkes@gmail.com
}

\author{
Abstract \\ The ipswich touch test manual book in improving skills for health cadre members \\ in detecting diabetic neuropathy
}

Background: Complications of diabetes can affect all organs of the body, especially the ends of the feet as diabetic foot. But this will not occur if diabetes treatment in properly and regularly. The early detection on nerve damage can do immediately to find neuropathy symptoms, which is a decrease in the sensitivity of the feet, by using a monofilament test. However, this tool is rarely available in health care units. Currently, a simple method for detecting neuropathy by the Ipswich Touch Test (IpTT). This technique can perform by health cadres, but it needs written instructions such as a guide or manual book.

Purpose: Knowing of the skills for health cadre members in detecting diabetic neuropathy by using ipswich touch test manual book.

Methods: The pretest-posttest quasi-experimental design with population was health cadre members taken by cluster sampling from Giri Roto and Dibal villages, Ngemplak District, Boyolali Regency. The sample divided by 2 groups and each a group of 60 participants of cadres. The evaluation by observing of the skills each health cadre members in detecting diabetic neuropathy before and after using ipswich touch test manual book.

Results: Based on data analysis using the chi-squared test, the p-value was $0.000(<0.005)$. This means that the research hypothesis accepted which states that there are differences in the skills on each health cadre members in detecting diabetic neuropathy before and after using ipswich touch test manual book.

Conclusion: There is improving in skills on each health cadre member in detecting diabetic neuropathy by using ipswich touch test manual book.

\section{Keywords: Ipswich touch test; Diabetic neuropathy; Skills; Cadre}

Pendahuluan: Komplikasi diabetes dapat menyerang seluruh organ tubuh khususnya ujung kaki berupa diabetic foot. Tetapi hal tersebut tidak akan muncul apabila perawatan diabetes dilaksanakan dengan baik, dan teratur. Sehingga terjadinya kerusakan saraf yang dapat segera terdeteksi seperi Neuropati yaitu penurunan sensitivitas rasa kaki. Neuropati dapat dideteksi dengan menggunakan monofilament test. Akan tetapi alat ini belum tentu tersedia di unit pelayanan kesehatan. Saat ini telah dibuat sebuah cara mendeteksi neuropati pada pasien diabetes yang sederhana tanpa alat dinamakan Ipswich Touch Test (IpTT). Teknik ini bahkan dapat dilakukan oleh non profesional antara lain kader kesehatan namun perlu instruksi tertulis seperti buku panduan.

Tujuan: Mengetahui perbedaan peningkatan keterampilan kader kesehatan dalam mendeteksi neuropati diabetik menggunakan buku panduan Ipswich Touch Test di Kecamatan Ngemplak Kabupaten Boyolali

Metode : Desain kuasi eksperimen pretest-posttest with control group sebagai populasi adalah kader kesehatan di Kecamatan Ngemplak Kabupaten Boyolali. Pengambilan sampel dilakukan cluster sampling sebanyak 2 kelompok kader yaitu kader di desa Giri Roto dan Dibal masing masing sebanyak 60 orang. Evaluasinya dengan melihat keterampilan kader sebelum dan sesudah menggunakan buku panduan uji sentuh ipswich

Hasil: Berdasarkan analisis data menggunakan uji Chi-Squared diperoleh hasil $p$-value $0.000(<0,005)$. Hal ini berarti Hipotesis penelitian diterima yang menyatakan bahwa terdapat perbedaan keterampilan kader dalam mendeteksi neuropati menggunakan buku panduan antara kader desa Dibal dan kader desa Giri Roto.

Simpulan: Terdapat peningkatan keterampilan setelah menggunakan buku panduan IpTT pada kader desa Dibal dan desa Giri Roto.

Kata Kunci : Ipswich Touch Test; Neuropati diabetic; Buku panduan; Kader; Keterampilan 


\section{PENDAHULUAN}

Penyakit Diabetes Mellitus (DM) hingga saat ini masih menjadi salah satu masalah kesehatan utama yang banyak dijumpai di masyarakat. Di seluruh dunia angka kejadiannya mengalami peningkatan dari waktu ke waktu salah satunya negara dengan jumlah penderita diabetes terbanyak adalah Indonesia. Pada tahun 2017 terdapat 451 juta penderita diabetes di seluruh dunia yang akan meningkat menjadi 693 juta pada tahun 2045. Data lain menyebutkan bahwa ada sekitar 5 juta kematian di seluruh dunia disebabkan oleh diabetes dengan pengeluaran biaya perawatan kesehatan mencapai USD 850 miliar (Cho. et al, 2018). Selain itu perlu menjadi perhatian adalah adanya perubahan demografis terpenting terhadap prevalensi diabetes dengan adanya peningkatan proporsi orang yang berusia> 65 tahun. Juga telah diketahui bahwa prevalensi diabetes lebih tinggi pada pria dibandingkan wanita di perkotaan yang diproyeksikan akan terjadi peningkatan dua kali lipat antara tahun 2000 dan 2030 (Wild, 2004).

Di Indonesia angka prevalensi diabetes mellitus juga meningkat khususnya pada orang dewasa yang diketahui pada tahun 2018 naik dari 6,9\% menjadi 8,5\% (Kementrian Kesehatan Republik Indonesia, 2018). Sedangkan untuk provinsi Jawa Tengah penyakit diabetes menjadi urutan ke 9 terbanyak dengan angka prevalensi sebesar 1,6\% khususnya di kabupaten Boyolali memiliki angka prevalensi sebesar 2,7\% atau sebanyak 6100 kasus. Di tingkat puskesmas, yaitu puskesmas Ngemplak Boyolali penyakit Diabetes termasuk dalam 10 penyakit terbanyak.

Diabetes dapat menyebabkan beberapa komplikasi yang dapat bermanifestasi secara akut atau kronis. Salah satu komplikasi yang sering dijumpai adalah gangguan pada kaki dimana kaki mudah terluka dan berlanjut menjadi bisul kaki (Fajriah, 2020). Komplikasi ini sangat ditakuti oleh penderita diabetes dimulai dari adanya kerusakan saraf sehingga penderita tidak dapat membedakan suhu panas dan dingin serta rasa sakit pun berkurang. Kerusakan pada saraf tersebut sering menyebabkan pengidap diabetes tidak menyadari adanya luka. Selain itu, kulit pada kaki menjadi kering dan mudah pecah akibatnya mudah terjadi borok dan infeksi. Sebagaimana hasil penelitian ditemukan bahwa kerusakan fungsi saraf lebih banyak ditemukan pada kerusakan otonom baik kaki kanan maupun kaki kiri $(89.9 \%$;
$85 \%$ ) sehingga diperlukan deteksi dini (Rosyida, 2016).

Mengingat komplikasi yang sering dan mudah terjadi maka diperlukan upaya deteksi dini. Hal ini juga harus menjadi perhatian khusus sebab saraf perifer memiliki kemampuan terbatas untuk beregenerasi. Dengan deteksi dini perkembangan kerusakan saraf perifer dapat dihambat atau dihentikan (Simanjuntak \& Simamora, 2020). Metode pemeriksaan kerusakan saraf perifer yang mengarah pada terjadinya neuropati dapat dideteksi dengan menggunakan monofilamen (Baraz, 2014). Pemeriksaan monofilamen tersebut dapat dilakukan untuk mendeteksi penurunan sensasi pada kaki sehingga meminimalkan risiko terjadinya ulkus kaki pada pasien diabetes yang belum terdiagnosis neuropati diabetik (Safitri, 2017). Hingga saat ini monofilamen belum tentu tersedia di unit pelayanan. Oleh karena itu telah dibuat sebuah cara menguji sensitivitas kaki untuk mendeteksi neuropati pada pasien diabetes yang dapat dilakukan dengan sederhana tanpa menggunakan alat khusus untuk menjawab permasalahan $\mathrm{di}$ atas. Instrumen tersebut dinamakan Ipswich Touch Test atau disingkat IpTT sering juga disebut Touch Toes Test sebagai pengganti tes monofilamen. (Fajriah, 2020). Kehandalannya telah teruji dalam mengidentifikasi risiko neuropati pada pasien diabetes sehingga membantu dalam mengatasi hambatan tidak tersedianya monofilament di setiap unit pelayanan kesehatan (Madanat, 2015). Keakuratannya diketahui bahwa sensitifitas hasil pemeriksaan berkisar antara $72.7 \%-100 \%$. Hal ini menandakan bahwa IPTT dapat mengkonfirmasi gejala neuropati pada penderita diabetes yang benar-benar mengalami neuropati. IpTT dinilai sebagai metode identifikasi dan skrining neuropati yang mudah dilakukan, murah dan sensitif yang dapat dilakukan oleh tenaga kesehatan baik di pelayanan kesehatan maupun di rumah. IpTT juga dapat digunakan sebagai alternatif jika tidak tersedia alat untuk mendeteksi gejala neuropati di pusat pelayanan kesehatan. (Kusumaningrum, 2015; Yuliani, 2017)

Karena tanpa alat dan sangat sensitif hasil pemeriksaannya, maka IpTT yang sederhana ini dapat digunakan oleh tenaga non-profesional dengan instruksi tertulis. Dampaknya telah terjadi peningkatan kesadaran terhadap komplikasi diabetes dan terjadi pemberdayaan orang disekitar pasien untuk melakukan pemeriksaan 
Efektifitas Buku Panduan Uji Sentuh Ipswich Dalam Meningkatkan Keterampilan Kader Kesehatan Mendeteksi Neuropati Diabetik

menggunakan IpTT sehingga dapat segera mencari pelayanan kesehatan yang tepat dan cepat bila dijumpai kondisi neuropati (Sharma, 2014).

Instruksi tertulis berupa buku panduan yang dapat digunakan oleh tenaga non-profesional seperti kader kesehatan perlu disiapkan. Melalui buku panduan diharapkan keterampilan kader melakukan deteksi menggunakan cara IpTT dapat terbentuk dengan baik. Berdasarkan hal tersebut penelitian ini dilakukan.

\section{METODE PENELITIAN}

Desain kuasi eksperimen dipilih dengan metode pre test - post test untuk melihat apakah terdapat perbedaan efektifitas penggunaan panduan IpTT dalam meningkatkan keterampilan kader kesehatan mendeteksi neuropati diabetik di kecamatan Ngemplak Kabupaten Boyolali. Data dikumpulkan pada bulan Agustus tahun 2020 berasal dari kader kesehatan di Kecamatan Ngemplak Kabupaten Boyolali sebagai populasi. Sampel sebagai partisipan ditetapkan dan diambil menggunakan cluster sampling yang berasal dari 2 desa sebanyak 120 kader kesehatan terdiri dari 60 orang kader kesehatan dari desa Giri Roto dan 60 orang dari desa Dibal. Data dikumpulkan menggunakan lembar observasi panduan Ipswich Touch Test ( Tes Sentuh Jari Kaki) yang dikembangkan dari buku Touch The Toes (Rayman, 2011).

Kegiatan pengumpulan data dimulai dengan mengobservasi kedua kelompok partisipan yang melakukan pemeriksaan IPTT sebelum diberi perlakuan berupa pemberian buku. Tahap selanjutnya kelompok partisipan Desa Giri Roto diberi perlakuan berupa pemberian buku panduan IPTT untuk dipelajari selama 1 minggu serta diberi penjelasan cara melakukan IPTT sesuai buku panduan tersebut. Penjelasan dilakukan dengan menerapkan protokol kesehatan Covid 19 yaitu menggunakan video yang dikirim melalui grup WhatsApp.

Sedangkan kelompok partisipan desa Dibal hanya diberi perlakuan berupa pemberian buku panduan IpTT tetapi tidak diberi penjelasan cara melakukan pemeriksaan IpTT. Tahap akhir dilakukan kembali observasi pemeriksaan IPTT pada kedua kelompok partisipan. Saat observasi juga menerapkan protokol kesehatan Covid 19 yaitu partisipan harus cuci tangan, jaga jarak dan menggunakan masker serta partisipan dibagi menjadi delapan kelompok kecil. Analisa data menggunakan uji Chi Square untuk menguji hipotesis penelitian dan penelitian ini telah lulus uji layak etik dari KEPK Poltekkes Surakarta No. LB.02.02/1.3/9385/2020. 


\section{HASIL}

Tabel 1. Karakteristik Partisipan ( $\mathrm{N}=120$ )

\begin{tabular}{|c|c|c|}
\hline $\begin{array}{l}\text { Distribusi Frekuensi } \\
\text { Karakteristik }\end{array}$ & $\begin{array}{c}\text { Kader Desa } \\
\text { Dibal } n=60\end{array}$ & $\begin{array}{c}\text { Kader Desa Giri Roto } \\
n=60\end{array}$ \\
\hline $\begin{array}{l}\text { Umur (Tahun) (Rentang) } \\
\text { (M } \pm \text { SD) }\end{array}$ & $\begin{array}{c}33-65 \\
(48.82 \pm 9.0)\end{array}$ & $\begin{array}{c}30-65 \\
(46.73 \pm 9.2)\end{array}$ \\
\hline $\begin{array}{ll}\text { Pendidikan } \\
-\quad \text { SD } \\
- & \text { SMP } \\
- & \text { SMA } \\
- & \text { Perguruan tinggi }\end{array}$ & $\begin{array}{c}5(8.3 \%) \\
10(18.3 \%) \\
29(48.3 \%) \\
15(25.0 \%)\end{array}$ & $\begin{array}{c}26(43.3 \%) \\
16(26.7 \%) \\
13(21.7 \%) \\
5(8.3 \%)\end{array}$ \\
\hline $\begin{array}{l}\text { Keterampilan Sebelum } \\
\text { Perlakuan } \\
\text { - Kategori Baik } \\
\text { - Kategori Buruk }\end{array}$ & $\begin{array}{l}17(28.3 \%) \\
43(71.7 \%)\end{array}$ & $\begin{array}{l}21(35 \%) \\
39(65 \%)\end{array}$ \\
\hline $\begin{array}{l}\text { Keterampilan Sesudah } \\
\text { Perlakuan } \\
\text { - Kategori Baik } \\
-\quad \text { Kategori Buruk }\end{array}$ & $\begin{array}{l}21(35 \%) \\
39(65 \%)\end{array}$ & $\begin{array}{l}38(63,3 \%) \\
22(36,7 \%)\end{array}$ \\
\hline
\end{tabular}

Berdasarkan tabel 1 karakteristik usia partisipan antara 33-65 tahun di desa Dibal dan 30-65 di desa Giri Roto berusia rata-rata (mean) 48.82 \pm 9.0 . sedangkan di desa Giri Roto rata-rata (mean) 46.73 \pm 9.2 . Pendidikan tertinggi adalah SMA (29/48.3\%) di desa Dibal dan SD (26/43.3\%) di desa Giri Roto. Keterampilan partisipan dalam kategori baik sebelum diberikan perlakuan dari desa Dibal $17(28.3 \%)$ dan dari desa Giri Roto $21(35 \%)$ dan sesudah diberikan perlakuan partisipan dalam kategori baik dari desa Dibal 21 (35\%) dan dari desa Giri Roto 38 (63,3\%).

Tabel 2. Perbedaan Keterampilan Partisipan Sebelum dan Sesudah Perlakuan

\begin{tabular}{|c|c|c|c|c|c|c|c|}
\hline \multirow[t]{2}{*}{$\begin{array}{c}\text { Keterampilan Sebelum } \\
\text { Perlakuan }\end{array}$} & \multicolumn{4}{|c|}{$\begin{array}{c}\text { Ketrampilan Sesudah } \\
\text { Perlakuan }\end{array}$} & \multicolumn{2}{|c|}{ Total } & \multirow[t]{2}{*}{$p$-value } \\
\hline & $\mathrm{n}$ & $\%$ & $\mathrm{n}$ & $\%$ & $\mathbf{N}$ & $\%$ & \\
\hline \multicolumn{8}{|l|}{ Kader Desa Dibal } \\
\hline Kategori Baik & 17 & 29 & 0 & 0 & 17 & 28 & \multirow[b]{2}{*}{0.000} \\
\hline Kategori Buruk & 4 & 6 & 39 & 65 & 43 & 72 & \\
\hline \multicolumn{8}{|l|}{ Kader Desa Giri Roto } \\
\hline Kategori Baik & 18 & 30 & 3 & 5 & 21 & 35 & \multirow[t]{2}{*}{0.000} \\
\hline Kategori Buruk & 20 & 33 & 19 & 32 & 39 & 65 & \\
\hline
\end{tabular}

Pada table 2 didapatkan perbedaan keterampilan pada kelompok partisipan desa Dibal sebelum dan sesudah diberikan perlakuan. Nilai $p$-value yang diperoleh yaitu 0.000 berarti lebih kecil dari 0,05 sehingga dapat disimpulkan terdapat perbedaan yang signifikan. Dengan demikian hipotesis yang berbunyi terdapat perbedaan 
Efektifitas Buku Panduan Uji Sentuh Ipswich Dalam Meningkatkan Keterampilan Kader Kesehatan Mendeteksi Neuropati Diabetik

keterampilan kader kesehatan sebelum dan sesudah diberikan buku panduan diterima. Perbedaan keterampilan pada kelompok kader desa Giri Roto sebelum dan sesudah diberikan perlakuan. Berdasarkan nilai $p$ Value yang diperoleh yaitu 0.000 berarti lebih kecil dari 0.05 dapat disimpulkan adanya perbedaan yang signifikan sehingga hipotesis yang berbunyi terdapat perbedaan keterampilan kader kesehatan sebelum dan sesudah diberikan buku panduan diterima.

Table 3. Perbedaan Keterampilan Partisipan Desa Dibal dan Desa Giri Roto

\begin{tabular}{|c|c|c|c|c|c|c|c|c|}
\hline \multirow[t]{3}{*}{ Keterampilan } & \multicolumn{4}{|c|}{ Partisipan } & \multicolumn{2}{|c|}{ Total } & \multirow[t]{3}{*}{$p$-value } & \multirow[t]{3}{*}{ OR } \\
\hline & \multicolumn{2}{|c|}{$\begin{array}{c}\text { Kader Desa Giri } \\
\text { Roto }\end{array}$} & \multicolumn{2}{|c|}{$\begin{array}{c}\text { Kader Desa } \\
\text { Dibal }\end{array}$} & & & & \\
\hline & $\mathrm{n}$ & $\%$ & $\mathrm{n}$ & $\%$ & $\mathbf{N}$ & $\%$ & & \\
\hline Kategori Baik & 38 & 64 & 21 & 35.6 & 59 & 100 & 0.003 & 3.208 \\
\hline Kategori Buruk & 22 & 36 & 39 & 63.9 & 61 & 100 & & \\
\hline
\end{tabular}

Pada table 3 terlihat bahwa diperoleh nilai $p$ Value 0,003 berarti lebih kecil dari 0,05 yang berarti terdapat perbedaan keterampilan yang signifikan antara partisipan dari desa Giri Roto dan partisipan desa Dibal. Dengan demikian hipotesis yang berbunyi terdapat perbedaan keterampilan kader kesehatan sebelum dan sesudah diberikan buku panduan diterima. Pada table 4 tersebut juga terlihat bahwa terdapat nilai OR 3,028 yang berarti ketrampilan kader yang diberi perlakuan berupa pemberian buku panduan dan diberi penjelasan memiliki peluang lebih terampil tiga kali dibanding kader yang diberi buku panduan tanpa diberi penjelasan.

\section{PEMBAHASAN.}

\section{Keterampilan Partisipan}

Partisipan sebagai kader kesehatan, selain pengetahuan juga harus memiliki keterampilan yang baik sehingga kader dapat menjalankan peran dan fungsinya di masyarakat. Keterampilan tersebut diantaranya saat ini adalah melakukan deteksi dini neuropati menggunakan IpTT pada penderita diabetes yang mudah, sederhana, tanpa alat dan dapat dilakukan oleh tenaga nonprofesional seperti kader kesehatan. Berdasarkan hasil penelitian diketahui bahwa kader kesehatan dari desa Dibal dan desa Giri Roto sebagian telah memiliki keterampilan pemeriksaan IpTT.

Keterampilan kader kesehatan di kedua desa tersebut semakin banyak yang baik setelah mendapat perlakuan berupa pemberian buku panduan dan khusus bagi kader desa Giri Roto ditambah dengan penjelasannya.
Hal serupa dijumpai pada kegiatan pelatihan deteksi dini risiko diabetic foot ulcer yang dilakukan di Depok Jawa Barat yang

menunjukkan hasil bahwa sebagian kader telah memiliki keterampilan deteksi dini sebelum diberikan pelatihan dan semua kader menjadi baik keterampilan setelah diberi pelatihan (Herlina, 2019). Tentu hal ini dapat dipahami karena pemeriksaan yang sederhana dan murah serta tanpa alat menjadikan pemeriksaan ini sangat mudah dipelajari dan digunakan oleh tenaga non professional (Sharma, 2014) dalam hal ini seperti kader kesehatan.

Tetapi dalam penelitian ini tidak semua kader keterampilan menjadi baik setelah diberikan perlakuan. Masih terdapat kader yang belum memiliki keterampilan yang baik sebagaimana dapat dilihat pada tabel 3. Hal ini dapat dipahami sebab walaupun kader mendapat berbagai macam variasi perlakuan seperti ceramah, tanya jawab, diskusi, demonstrasi dan diakhiri dengan praktik tapi bila latar belakang pendidikan kurang memadai seperti hanya berpendidikan dasar maka informasi dan keterampilan baru sulit dikuasai sehingga tidak ada perbedaaan sebelum dan sesudah perlakuan (Sulistiyawati, 2019). Diketahui bahwa kader yang menjadi partisipan dalam penelitian ini yang berpendidikan SD ada 25 orang $(21 \%)$ dapat menjawab permasalahan diatas.

\section{Efektifitas Buku Panduan}

Penelitian ini menunjukkan bahwa keterampilan IpTT yang dimiliki kader desa Dibal dan desa Giri Roto sangat berbeda setelah 
Efektifitas Buku Panduan Uji Sentuh Ipswich Dalam Meningkatkan Keterampilan Kader Kesehatan Mendeteksi Neuropati Diabetik

diberikan perlakuan berupa pemberian buku panduan. Keterampilan yang berbeda tersebut dapat terjadi mengingat bahwa perlakuan yang diberikan pada kader desa Giri Roto selain diberikan buku panduan juga diberikan penjelasan nya sedangkan pada kelompok kader desa Dibal tidak diberi penjelasan. Pada dasarnya pemberian buku saku sudah dapat mengubah keterampilan kader menjadi lebih baik sebagaimana penelitian penggunaan buku saku dibanding ceramah (Eka, 2018).

Hal ini terbukti sebagaimana dapat dilihat pada tabel 3 yang menyebutkan bahwa di kedua kelompok respon terjadi perbedaan yang signifikan antara sebelum dan sesudah pemberian buku saku. Tetapi keterampilan kader akan menjadi lebih baik lagi bila pemberian buku saku diiringi dengan penjelasan. Hal ini dapat dibuktikan sebagaimana dapat dilihat pada hasil penelitian ini bahwa keterampilan kader desa Giri Roto yang diberikan buku panduan dan penjelasannya tiga kali lebih baik dari kader Dibal yang hanya diberikan buku saku saja.

Peningkatan kapasitas kader kesehatan dapat dilakukan seperti melakukan pelatihan yang dapat diukur keberhasilannya melalui evaluasi pengetahuan dan keterampilan. Namun pada aspek keterampilan para kader harus diberi kesempatan praktek berulang ulang agar ketrampilan yang dimiliki kader menjadi sangat baik. Hal tersebut pernah dilakukan dalam pelatihan dan simulasi cara mendeteksi risiko neuropati bagi kader di Depok Jawa Barat. Setiap kader diberi kesempatan melakukan pemeriksaan deteksi dengan menggunakan modul pelatihan yang sudah disiapkan. Hasilnya terdapat peningkatan pengetahuan dan keterampilan kader kesehatan dalam mendeteksi risiko neuropati pada penderita diabetes (Herlina, 2019). Selanjutnya agar keterampilan menjadi sangat baik dianjurkan kader melakukannya berulang ulang seperti pada penelitian lain tentang keterampilan pijat bayi. Kader diminta untuk mendapatkan 5 bayi yang berbeda untuk dilakukan pijat bayi agar ketrampilan pijat bayi dapat dilatih berulang ulang (Prananingrum, 2017).

Pemeriksaan IpTT dinilai sebagai metode identifikasi dan skrining neuropati yang mudah dilakukan, efektif, murah, dan sensitif serta spesifik sehingga tenaga kesehatan baik di pelayanan kesehatan maupun di rumah dapat mengaplikasikan metode ini (Kusumaningrum, 2015). Bahkan pemeriksaan IpTT dapat dilakukan oleh tenaga non profesional dengan instruksi tertulis seperti menggunakan buku panduan namun tetap didampingi dengan penjelasan penggunaan buku panduan tersebut. Selain itu diperlukan juga latihan berulang ulang.

\section{SIMPULAN}

Deteksi dini neuropati menggunakan IPTT dapat dilakukan tenaga non profesional sebab sederhana, mudah dan tanpa alat tetapi memiliki keakuratan yang tinggi. Mempelajarinya keterampilan pemeriksaan IpTT dapat dilakukan dengan mudah menggunakan buku panduan. Akan lebih baik lagi bila didampingi dengan penjelasan oleh tenaga kesehatan dan berlatih berulang ulang maka agar ketrampilan dapat dimiliki oleh kader dengan sangat baik.

\section{DAFTAR PUSTAKA}

American Diabetes Association. (2004). Global prevalence of diabetes. Diabetes care, 27(5).

Baraz, S., Zarea, K., Shahbazian, H. B., \& Latifi, S. M. (2014). Comparison of the accuracy of monofilament testing at various points of feet in peripheral diabetic neuropathy screening. Journal of Diabetes \& Metabolic Disorders, 13(1), 19.

Cho, N., Shaw, J. E., Karuranga, S., Huang, Y., da Rocha Fernandes, J. D., Ohlrogge, A. W., \& Malanda, B. (2018). IDF Diabetes Atlas: Global estimates of diabetes prevalence for 2017 and projections for 2045. Diabetes research and clinical practice, 138, 271-281.

Fajriyah, N. N., Aktifah, N., \& Mugiyanto, E. (2020). Paket Edukasi dan Deteksi Dini Meningkatkan Perilaku Perawatan Kaki Diabetisi di Puskesmas Kabupaten Pekalongan. Gaster, 18(1), 12-20.

Herlina, S., Ladesvita, F., \& Florensia, L. (2019). Meningkatkan pengetahuan dan kemampuan kader kesehatan melalui pelatihan deteksi dini risiko diabetic foot ulcer. Sabdamas, 1(1), 182186. 
Efektifitas Buku Panduan Uji Sentuh Ipswich Dalam Meningkatkan Keterampilan Kader Kesehatan Mendeteksi Neuropati Diabetik

Kementerian Kesehatan Republik Indonesia. (2018). Riskesdas: angka kejadian 10 penyakit di indonesia . French. Retrieved from http://www.who.int/about/licensing/\%5Cnhttp://ap ps.who.int/iris/bitstream/10665/204871/1/9789241 565257 eng.pdf

Kusumaningrum, N. S. D. (2015). Ipswich touch test sebagai metode sederhana untuk skrining diabetic foot ulcer: studi literatur.

Madanat, A., Sheshah, E., Badawy, E. B., Abbas, A., \& Anas, A. B. (2015). Response to the comment by Vas PR et al:" PR Vas, S. Sharma, G. Rayman, Utilizing the Ipswich Touch Test to simplify screening methods for identifying the risk of foot ulceration among diabetics: comment on the Saudi experience. Prim. Care Diabetes (2015) http://dx. doi. org/10.1016/j. pcd. 2015.01. 003.". Primary care diabetes, 9(5), 401.

Prananingrum, R., Untari, I., \& Kusudaryati, D. P. D. (2017). Peningkatan Pengetahuan dan Ketrampilan Kader Posyandu Balita Melalui Praktek Pijat Bayi Menuju Balita Sehat. URECOL, 249-254.

Rayman, G., Vas, P. R., Baker, N., Taylor, C. G., Gooday, C., Alder, A. I., \& Donohoe, M. (2011). The Ipswich Touch Test: a simple and novel method to identify inpatients with diabetes at risk of foot ulceration. Diabetes care, 34(7), 15171518.

Rosyida, K., \& Safitri DK, N. (2016). Gambaran Neuropati Perifer pada Diabetisi di Wilayah Kerja Puskesmas Kedungmundu Semarang (Doctoral dissertation, Faculty of Medicine).
Safitri, V. A., Rosdiana, D., \& Astari, R. V. (2018). Gambaran Hasil Pemeriksaan Monofilamen pada Pasien Diabetes Melitus (DM) yang berkunjung ke Poliklinik Penyakit Dalam RSUD Arifin Achmad Provinsi Riau. Jurnal IImu Kedokteran, 11(2), 3439.

Sharma, S., Kerry, C., Atkins, H., \& Rayman, G. (2014). The Ipswich Touch Test: a simple and novel method to screen patients with diabetes at home for increased risk of foot ulceration. Diabetic medicine, 31(9), 1100-1103.

Simanjuntak, G. V., \& Simamora, M. (2020). Lama menderita diabetes mellitus tipe 2 sebagai faktor risiko neuropati perifer diabetik. Holistik Jurnal Kesehatan, 14(1), 96-100.f

Sulistiyawati, I., \& Pratiwi, I. G. (2019). Pengaruh pelatihan terhadap keterampilan kader posyandu dalam pencatatan kms balita. Jurnal kebidanan akademi kebidanan jember, 3(1), 1-7.

Widyastuti, D. E. (2018). Perbandingan Pendidikan Kesehatan Menggunakan Buku Saku dengan Metode Ceramah Terhadap Tingkat Pengetahuan Ibu Hamil Tentang Tanda Bahaya Kehamilan. Profesi (Profesional Islam): Media Publikasi Penelitian, 16(1), 84-88.

Yuliani, K., Sulaeha, S., Sukri, S., \& Yusuf, S. (2017). Check Up Diabetic Foot, Deteksi Dini Risiko Luka Kaki Diabetes Pada Pasien Diabetes Mellitus di Makassar: Uji Sensitifitas dan Spesifisitas. Jurnal Administrasi dan Kebijakan Kesehatan Indonesia, 1(1), 62-65. 